\title{
A Fault Severity Index for Stator Winding Faults Detection in Vector Controlled PM Synchronous Motor
}

\author{
M. Hadef ${ }^{\dagger}$, A. Djerdir**, N. Ikhlef*, M.R. Mekideche* and A. O. N'diaye**
}

\begin{abstract}
Stator turn faults in permanent magnet synchronous motors (PMSMs) are more dangerous than those in induction motors (IMs) because of the presence of spinning rotor magnets that can be turned off at will. Condition monitoring and fault detection and diagnosis of the PMSM have been receiving a growing amount of attention among scientists and engineers in the past few years. The aim of this study is to propose a new detection technique of stator winding faults in a three-phase PMSM. This technique is based on the image analysis and recognition of the stator current Concordia patterns, and will allow the identification of turn faults in the stator winding as well as its correspondent fault index severity. A test bench of a vector controlled PMSM motor behaviors under short circuited turn in two phases stator windings has been built. Some experimental results of the phase to phase short circuits have been performed for diagnosis purpose.
\end{abstract}

Keywords: Permanent magnet synchronous motor(PMSM), Stator turn faults Park's vector approach, Image composition, Pattern recognition, Fault severity index (FSI).

\section{Introduction}

Thanks to their advantages such as high efficiency and power density, permanent synchronous motors (PMSMs) are becoming more and more popular and at the present they are replacing induction motors in some application fields. The condition monitoring of PMSM drives has become a critical problem for various industrial applications because a sudden drive failure can cause serious damage and economical losses [1-3]. The majority of the stator winding fault is caused by the breakdown of turn-to-turn insulation as a result of the voltage, current or thermal stress acted on the stator winding. In early of this failure, the motor may still operate. Stator turn faults in PM motors are related to the short-circuit of a few turns of a stator winding. The short circuit is usually within the coil or between the coils of a phase. A large current follows through the shorted turns of the stator winding, which finally results in reversible damage of the stator [4-6]. In order to increase PMSM performance, raise their lifetime, and lower their high costs, fault prediction are necessary. Rapid diagnosis and correct of a failure in an electrical machine ensures optimum reliability, maximum safety, maintenance on time prevention and rescue of electric motors in applications of high power and low. In recent years, the topic of fault diagnosis of electrical drives has received a lot of attention. Methodologies have been

$\dagger$ Corresponding Author: Laboratoire L2EI. Université de Jijel, Algérie. (hadef_mounir@yahoo.fr)

* Laboratoire L2EI. Université de Jijel, Algérie. (\{Ikhlefnabil, mek_moh\}@yahoo.fr)

* Laboratoire IRTES-SET. Université de Technologie de BelfortMontbéliard, FRANCE. (\{Abdesslem.Djerdir, abdoul-ousman.n-diaye\} @utbm.fr)

Received: July 18, 2014; Accepted: July 11, 2015 developed to determine faults in bearings and gears, bars in the rotors of induction machines, short and open circuit in stator windings and inverter switchers, rotor demagnetization and eccentricity [7-13]. The methods of fault detection and diagnosis can be categorized into three groups.

The first group is the model-based method which uses a mathematical model to describe the model operating condition of the electrical machine. The second group is the signal-based method. This method is based on analysis of the measured signals $[1-3,9,10,12]$. Suitable features of the measured signals are used to evaluate the operating condition of the electrical motor. These features are extracted by using the time-domain analysis, frequencydomain analysis or with more sophisticated techniques like time frequency or wavelet analysis. The third group is the artificial intelligence based methods (AI). Fuzzy logic [14, 15], neural networks [16, 17], support vector machine are popular approaches used for fault detection and diagnosis (FDD) of complex systems. With the increasing demand to maintain a higher level of safety, performance, and reliability against any probable abnormal conditions.

Many effective techniques have been presented to detect inter-turn short in the past years, with majority of them focused on induction motors. Diagnosis techniques for PM motors are fewer in number compared with induction motors. In order to carry out an online or offline diagnosis scheme, it is highly to use an easy-to-calculate the severity index with low computational burden. As in [1] it is proposed to diagnose incipient demagnetization faults by applying an online monitoring of the zero-sequence voltage component (ZSVC). A fault severity index with low computational burden, allows quantifying the severity of a 


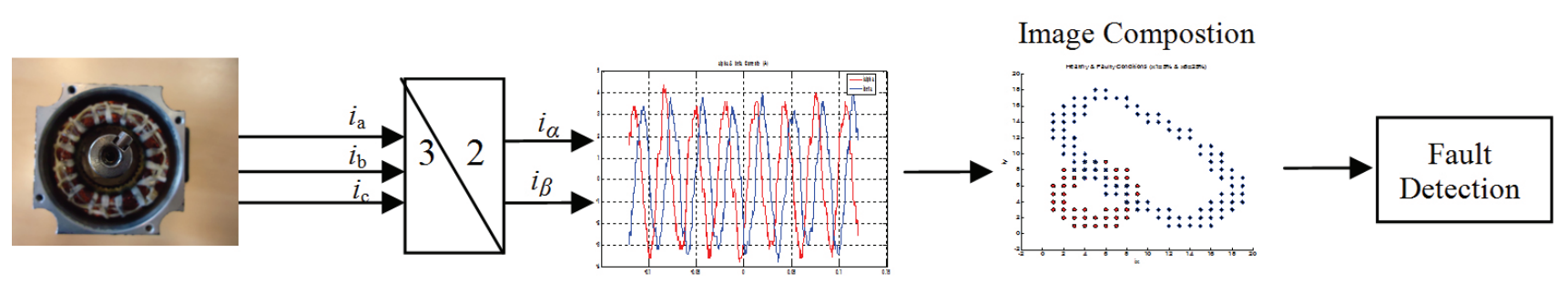

Fig. 1. Proposed diagnosis approach.

demagnetization fault. This fault index is easily obtained by comparing back-emf with the reference back-emf when the machine was healthy. In [2] an approach to detect abnormalities in the winding of a PM machine which uses the injection of HF voltages and the processing of the modulated HF currents is proposed. The difference between the measured saliency with respect to the expected saliency is used to derive an error saliency that can be used to quantify the severity of a fault and indicate the condition of the drive. In [9] the Eigen value is used as a fault severity index to predict the degree of mixed eccentricity fault in induction motor. This fault severity index is defined by evaluating the amplitudes of many eccentricity related harmonics and these values are compared to these of a healthy machine.

In [10] the authors introduce novel indices for broken rotor bars diagnosis in three-phase induction motors based on wavelet coefficients of stator current in a specific frequency band. The two indices make it possible to diagnose the fault and number of broken rotor bars in different load.

In [11] the authors indicated that so far 12 distinct indices have been introduced for eccentricity fault diagnosis in three-phase induction motors. These indices have capability to be used in non-invasive fault diagnosis techniques. In [18] a diagnosis method based on a global fault index applied to the instantaneous power signal and line current signal for detection of broken rotor bars was proposed. In [19] a proposed algorithm based on the principal components analysis (PCA) allows an automatic classification of stator fault. With the obtained eigenvectors, the stator currents are projected into the new eigenvector state space and a severity index is easily calculated. Finally, in [20] an indicator of the degree of asymmetry defined as the ratio between the amplitude of the spectral component at the frequency of $2 f$ and the DC level of the differential current Park's vector, gives enhanced sensitivity to detect incipient winding turn-to-turn faults.

In this context, our contribution leads to good representations, it requires a feature extraction steps in order to distinguish a faulty machine from a healthy one and afterwards measure fault index severity. This paper proposes a fault detection technique. It based on the identification of the stator current Concordia patterns via an image processing. It is organized as follows: the proposed technique is presented in section 2. It allows to directly derive a fault severity index. This latter conveys the information about the presence of the fault and its severity in the vector controlled PMSM. Experimental results for several short-circuited turns for both phase $a$ and phase $b$ are reported in section 3 , in order to validate the feasibility of the proposed technique. Finally, section 4 contains the concluding remarks.

\section{Pattern Analysis for Motor Fault Diagnosis}

The proposed pattern recognition based fault diagnosis contains three parts: Park's vector representation of the phase-currents $\left(i_{\mathrm{a}}, i_{\mathrm{b}}, i_{\mathrm{c}}\right)$, an image composition and a fault detection. Fig. 1 shows the structure of the proposed algorithm.

A short-circuit in the stator effectively introduces an extra winding in the motor's winding structure. Three phase star connected stator winding with two short-circuit on the stator phase $a$ and $b$ are shown in Fig. 2. The phases $a$ and $b$ windings are described with two subwindings $a_{1}$, $a_{2}$ and $b_{1}, b_{2}$ in series respectively. While subwindings $a_{2}$ and $b_{2}$ are shorted via the resistors $R_{\mathrm{af}}$ and $R_{\mathrm{bf}} . R_{\mathrm{a}, \mathrm{b}, \mathrm{c}}$ are the stator phase resistances, $R_{\mathrm{a} 2}$ and $R_{\mathrm{af}}$ are the resistance of subwinding $a_{2}$ and the contact resistance due to the turn-toturn short respectively. $R_{\mathrm{b} 2}$ and $R_{\mathrm{bf}}$ are the resistance of subwinding $b_{2}$ and the contact resistance due to the turn-toturn short respectively. $L_{\mathrm{a}, \mathrm{b}, \mathrm{c}}$ are the phase self inductances. $L_{\mathrm{a} 2}$ denotes the self inductance of the faulty subwinding $a_{2}$. $L_{\mathrm{b} 2}$ denotes the self inductance of the faulty subwinding $b_{2}$. $M_{\mathrm{a} 1 \mathrm{a} 2}, M_{\mathrm{a} 2 \mathrm{~b} 1}, M_{\mathrm{a} 2 \mathrm{~b} 2}$ and $M_{\mathrm{a} 2 \mathrm{c}}$ are the mutual inductance

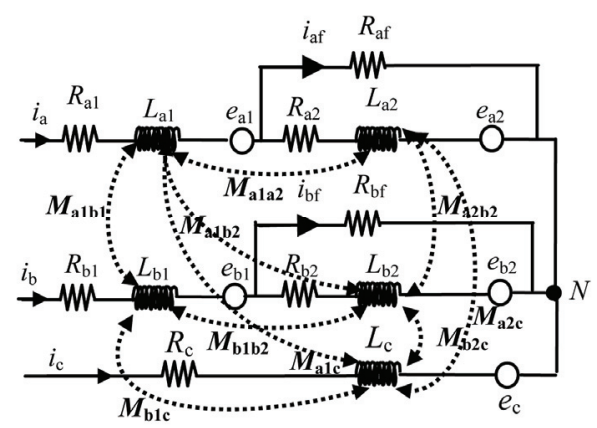

Fig. 2. Equivalent circuit of PMSM with inter turn fault in phase $a$ and $b$. 
between $a_{2}$ and respectively $a_{1}, b_{1}, b_{2}$ and $c . v_{\mathrm{a}}, v_{\mathrm{b}}, v_{\mathrm{c}}$ are stator voltage of phase $a, b$ and $c$ respectively. $i_{\mathrm{a}}, i_{\mathrm{b}}, i_{\mathrm{c}}$ are stator currents of healthy phases $a, b$ and $c$ respectively. $i_{\text {af }}$ and $i_{\mathrm{bf}}$ are stator currents of faulty phases $a, b . e_{\mathrm{a}}, e_{\mathrm{b}}, e_{\mathrm{c}}$ are back-EMF of healthy phases $a, b, c$ respectively. $e_{\mathrm{a} 2}$ and $e_{\mathrm{b} 2}$ are back-EMF of the faulty phase $a$, and $b$.

\subsection{Park's vector approach}

Park's transformation is a mathematical tool that is able to show interesting properties and describe behaviour of a three-phase system with particular imbalance, asymmetry and distortion properties. The three phase PMSM motor $\alpha \beta$ currents are given as a function of mains phase-currents $\left(i_{\mathrm{a}}, i_{\mathrm{b}}, i_{\mathrm{c}}\right)$ by

$$
\left\{\begin{array}{c}
i_{\alpha}=\sqrt{\frac{2}{3}} i_{a}-\frac{1}{\sqrt{6}} i_{b}-\frac{1}{\sqrt{6}} i_{c} \\
i_{\beta}=\frac{1}{\sqrt{2}} i_{b}-\frac{1}{\sqrt{2}} i_{c}
\end{array}\right.
$$

Under ideal condition, the three-phase currents lead to a Park's vector with

$$
\left\{\begin{array}{c}
i_{\alpha}=\frac{\sqrt{6}}{2} I_{m} \sin (\omega t) \\
i_{\beta}=\frac{\sqrt{6}}{2} I_{m} \sin \left(\omega t-\frac{\pi}{2}\right)
\end{array}\right.
$$

where $I_{\mathrm{m}}$ is the maximum value of the supply phase current, $\omega$ is the angular supply frequency and $t$ is the time variable.

The so-called Concordia vector is a plot between $i_{\alpha}$ and $i_{\beta}$ which is of circular pattern centered at the origin. This acts as a reference figure that allow the detection of abnormal conditions by monitoring the deviations of acquired pattern [21, 22].

\subsection{Image composition}

The criteria to choose the most appropriate signals for accurate fault recognition in electrical motors consist of sensitivity of the signals to the fault. The $\alpha \beta$ stator currents can be diagnosed via image analysis and recognition. In the image composition stage the $\alpha \beta$ stator currents are represented as an image in order to be used in pattern recognition approach [19], [22]. Each sample of $\alpha \beta$ stator currents will be considered as a binary pixel belonging to the object contour with coordinates $\left(i_{\mathrm{x}}, i_{y}\right)$ given as

$$
\left\{\begin{array}{l}
i_{x}=\operatorname{round}\left(\left(i_{\alpha}-o f f s_{2} t_{-} x\right) k\right) \\
i_{y}=\operatorname{round}\left(\left(i_{\beta}-o f f s_{-} t_{-}\right) k\right)
\end{array}\right.
$$

with

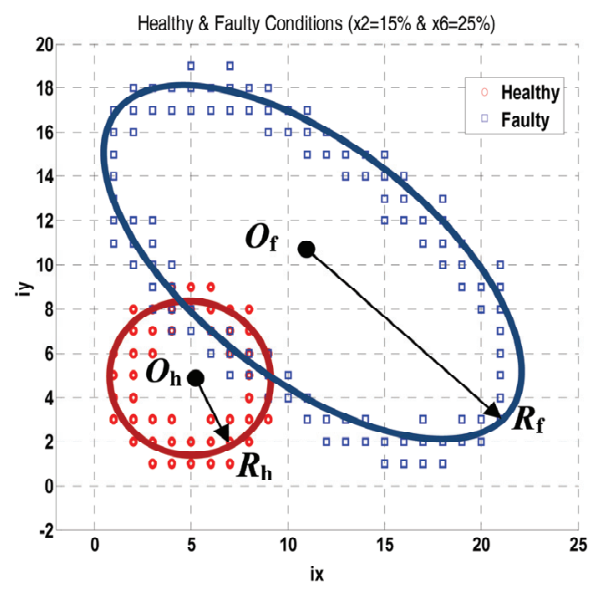

Fig. 3. Image plan for the stator current vector pattern. 2-D vector samples.

$$
\left\{\begin{array}{l}
\text { offset_} \_x=\min \left(i_{\alpha}\right)-1 \\
\text { offset_y }=\min \left(i_{\beta}\right)-1
\end{array}\right.
$$

Considering an object with each pixel $\left(x_{\mathrm{i}}, y_{\mathrm{i}}\right)$ as a gray level $I\left(x_{\mathrm{i}}, y_{\mathrm{i}}\right)$. A binary image can be considered as a particular case of a grey image with $I\left(x_{\mathrm{i}}, y_{\mathrm{i}}\right)=1$ for pixels that belongs to an object, and $I\left(x_{\mathrm{i}}, y_{\mathrm{i}}\right)=0$ for pixels that belongs to the background. The PMSM motor generates a circle pattern in healthy conditions and an elliptic pattern in faulty conditions where a fault in stator winding appears. In order to recognize the pattern type, it becomes necessary to establish the boundary of the region, as well as the scattering of the $i_{\mathrm{x}}$ and $i_{y}$ coordinates in relation of their average trajectory.

\subsection{Index fault detection}

Once a digital image has been segmented, measurements can be performed to investigate the shape and size of the spatial pattern in that image as shown in Fig. 3. By sorting the $i_{\mathrm{x}}$ and $i_{y}$ coordinates of each sample of $\alpha \beta$ stator currents belonging to the region contour and plotting the results in $2 \mathrm{D}$ plane, a fault severity index which varies between zero and one will be given as

$$
F S I=1-\frac{R_{h}}{R_{f}}
$$

where $\mathrm{R}_{h}$ denote the radius of the circular pattern in healthy conditions, and $\mathrm{R}_{f}$ denote the major axis of the elliptic pattern in faulty conditions.

\section{Experimental Setup and Results}

In order to validate the theoretical analysis, a series of experiments were conducted for detection of inter-turn 


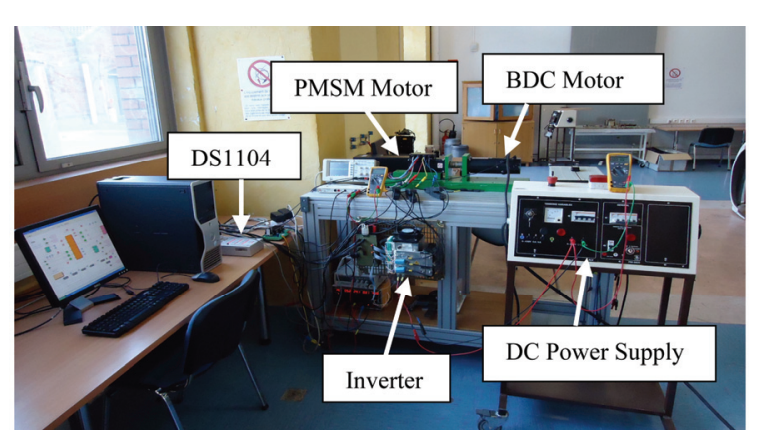

Fig. 4. Experimental setup.

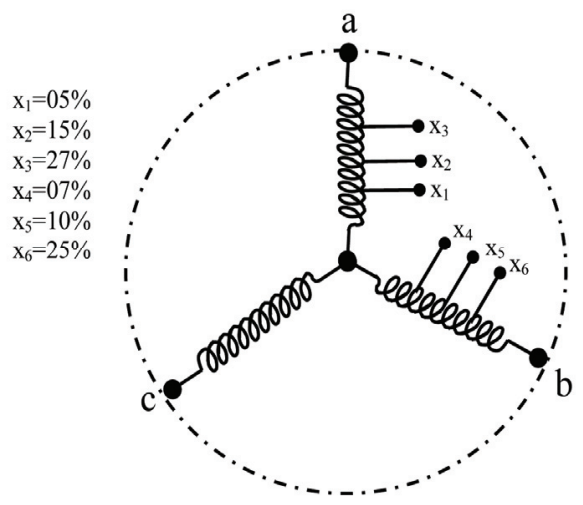

Fig. 5. Stator winding configuration of the PMSM under test.

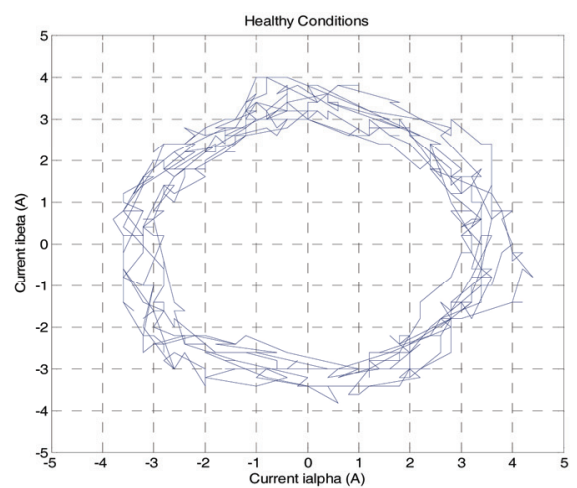

(a)

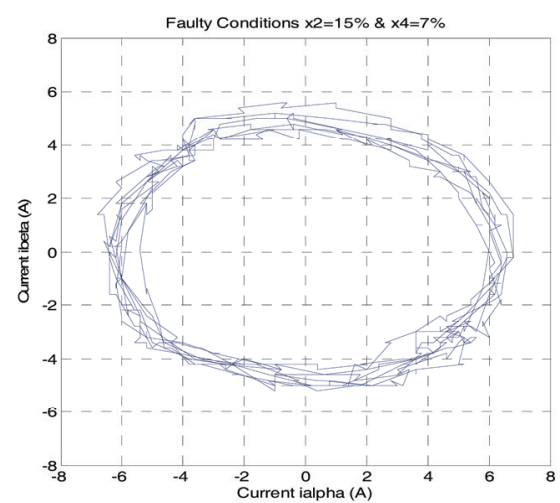

(c) short circuits in stator windings of a vector controlled PM motor. The setup shown in Fig. 4 consists of a 3-pole, 1KW, 3000rpm coupled to a brushless dc motor. An IGBT-based inverter, a dSPACE DS1104 board, and a measurement currents system employing two Hall Effect sensors. The rotor position and speed are measured by an encoder having a resolution of 1024 pulses per mechanical turn. The stator windings were modified by the addition of six connections to the stator coils for two-phases as shown in Fig. 5. To verify the robustness of the drive, experiments have carried out under load conditions where the test motor operates at a speed of $1000 \mathrm{rpm}$. This latter was tested with several numbers of short circuited turns.

The Park's modelling approach has been used and seems to be good to be applied on the diagnosis of interturn stator winding short-circuits in PMSMs. In the implemented vector control $d-q$ reference frame is fixed to the rotor flux position which is defined by the rotor mechanical angle $\theta_{\mathrm{r}}$. The PM synchronous motor is fed by a PWM inverter. In indirect torque control this latter is controlled by the quadrature axis component of the stator current $i_{\mathrm{q}}{ }^{*}$. The rotor flux is controlled by the direct axis component $i_{\mathrm{d}}{ }^{*}$. In order to produce optimum torque $i_{\mathrm{d}}{ }^{*}$ reference is set to zero $\left(i_{\mathrm{d}}^{*}=0\right)$.

The motor speed is regulated by a control loop which produces the torque control signal $i_{\mathrm{q}}{ }^{*}$. The operator may

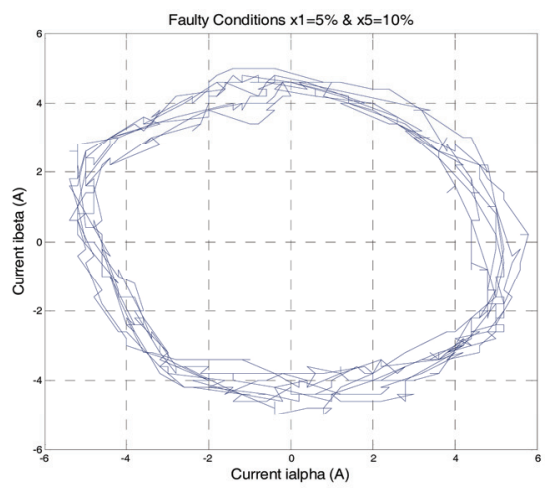

(b)

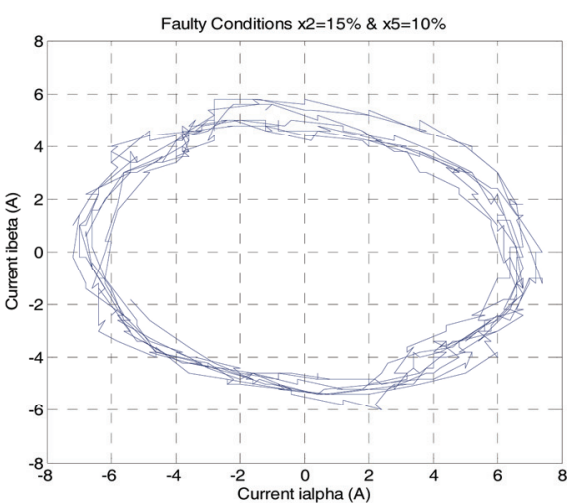

(d)

Fig. 6. Experimental locus of $\alpha \beta$ current: (a) Healthy conditions; (b) Faulty conditions (x1=5\% \& x5=10\%); (c) Faulty conditions ( $2=15 \%$ \& $x 4=7 \%$ ); (d) Faulty conditions ( $2=15 \%$ \& $x 5=10 \%$ ). 
supervise the test bench through Controldesk software specially dedicated to Dspace device. Fig. 6(a) shows the current Park's representation of healthy operating mode for load conditions. It is clearly seen that the space vector representation of the current is a circular locus. After analysing the stator currents in healthy mode, several experimental results were obtained in the case of faulty operating mode. The PMSM motor was initially operated under phase to phase short circuit fault. Fig. 6(b), presents the corresponding $\alpha \beta$ vector currents representation with $5 \%$ of short circuited turns of phase ' $a$ ' and $10 \%$ of short circuited turns of phase ' $b$ '. In this figure the $\alpha \beta$ vector currents representations are quit distinct from a perfect circle.

Fig. 6(c), shows the experimental results of $\alpha \beta$ vector pattern when a fault is considered with $15 \%$ of short circuited turns of phase ' $a$ ' and $7 \%$ of short circuited turns of phase ' $b$ '. The current space vector representation is elliptical pattern and the ellipticity increases with the severity of the fault and the major axis orientation depends on faulty phase. Fig. 6(d) shows the experimental results of the obtained pattern stator currents in $\alpha \beta$ plane when the

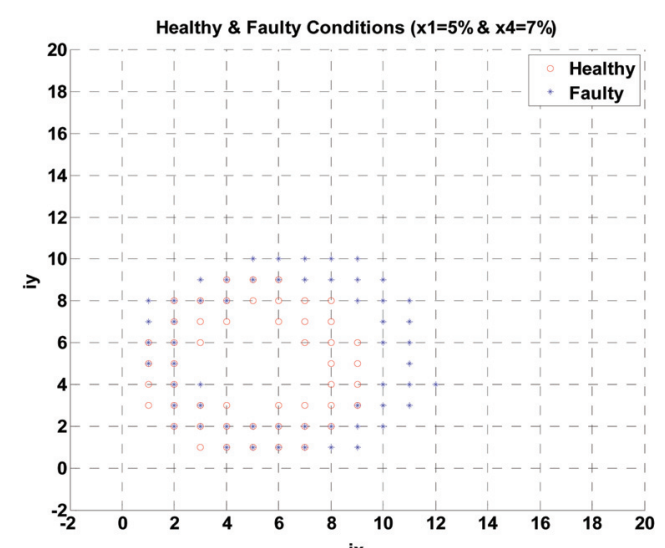

(a)

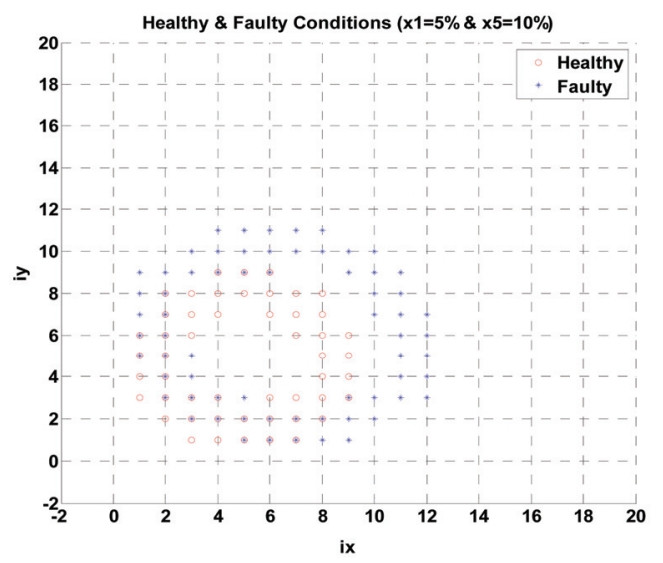

(b)

Fig. 7. Image plan for the stator current vector pattern. 2-D vector samples: (a) Healthy conditions \& Faulty conditions ( $\mathrm{x} 1=5 \%$ \& $\mathrm{x} 4=7 \%)$; (b) Healthy conditions \& Faulty conditions ( $1=5 \%$ \& $1=5=10 \%$ ). motor was operated with a stator winding fault of $15 \%$ of short circuited turns of phase ' $a$ ' and $10 \%$ of short circuited turns of phase ' $b$ '.

In order to validate the applicability of the proposed current state pattern recognition for fault detection and diagnosis method, several experimental results of PMSM motor in healthy and faulty conditions were considered, and the image processing based system was applied. In the feature extraction step the key features used for fault diagnosis are: the vector points of the object, and the severity fault index (FSI). As shown in Fig. 7, Fig. 8 and Fig. 9 respectively (red locus) when the PMSM was initially operated without any fault, the corresponding pattern associated with $\alpha \beta$ stator currents is practically a circle centered at $O_{\mathrm{h}}(5,5)$ of the $i \mathrm{x}$ and $i \mathrm{y}$ coordinates. However, Fig. 7(a) and 7(b) indicate that if the motor has $5 \%$ of short circuited turns of phase 'a' and $7 \% \& 10 \%$ of short circuited turns of phase ' $b$ ', the representation of its patterns associated with $\alpha \beta$ stator currents is an ellipse centered at $O_{\mathrm{f}}(6,5)$ and $O_{\mathrm{f}}(6.5,6)$ respectively. It can be seen in Fig. 8 that in the case of $15 \%$ of short circuited turns of phase ' $a$ ' and $7 \% \& 10 \%$ of short circuited turns

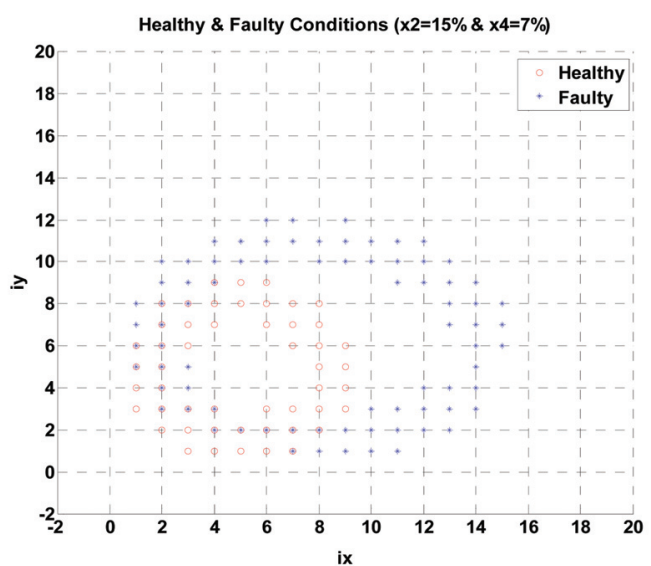

(a)

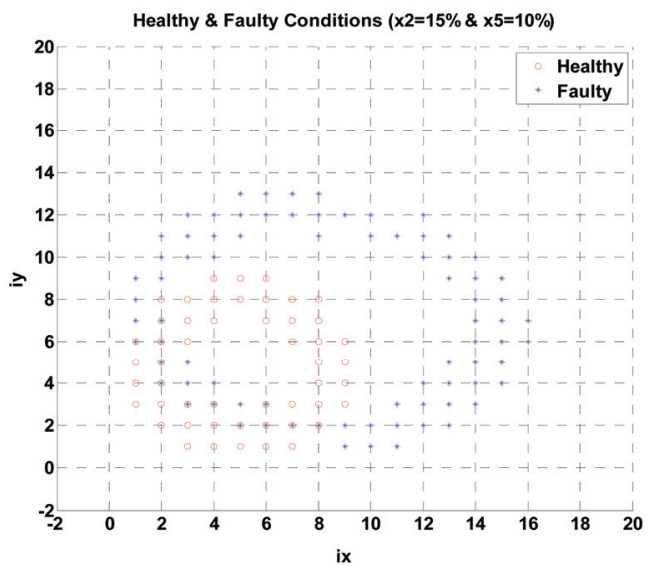

(b)

Fig. 8. Image plan for the stator current vector pattern. 2-D vector samples: (a) Healthy conditions \& Faulty conditions ( $\mathrm{x} 2=15 \%$ \& $\times 4=7 \%)$; (b) Healthy conditions \& Faulty conditions (x $2=15 \% \&$ x $5=10 \%$ ). 


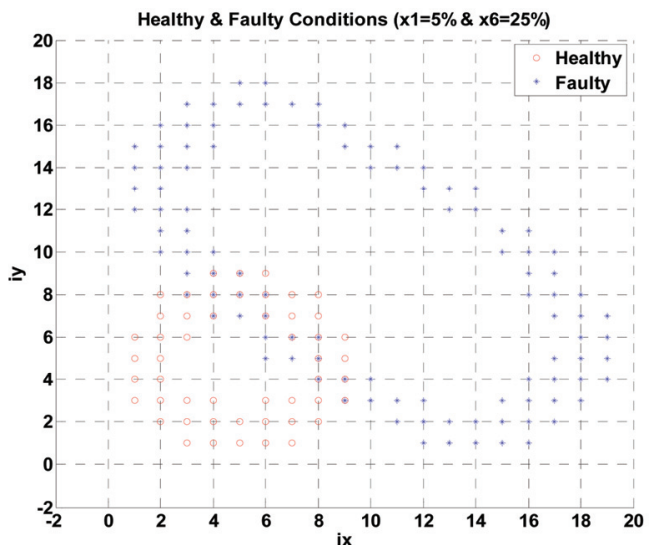

(a)

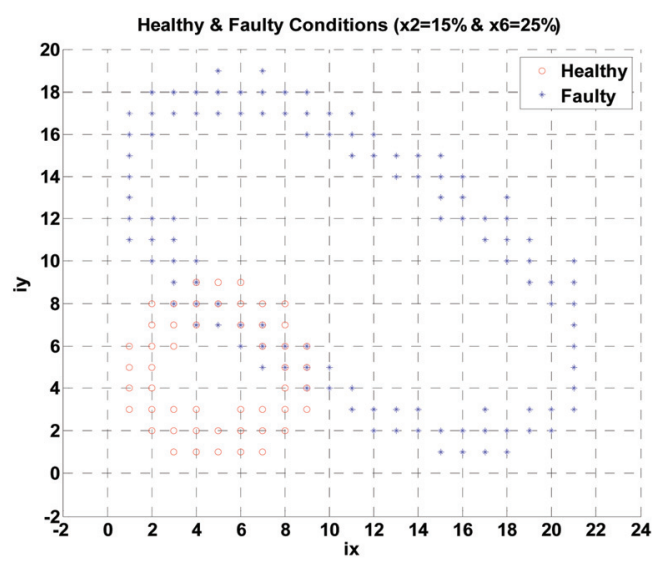

(b)

Fig. 9. Image plan for the stator current vector pattern. 2-D vector samples: (a) Healthy conditions. \& Faulty conditions ( $\mathrm{x} 1=5 \%$ \& $\mathrm{x} 6=25 \%)$; (b) Healthy conditions. \& Faulty conditions ( $\mathrm{x} 2=15 \% \& \mathrm{x} 6=25 \%)$.

of phase ' $b$ ', the representation of its $\alpha \beta$ stator currents pattern is an ellipse centered at $O_{\mathrm{f}}(8,6.5)$ and $O_{\mathrm{f}}(8.5,7)$ Respectively, where the major and minor axes are longer than those in Fig. 7 for the same load conditions. The major axis orientation of each ellipse is associated to the severe faulty phase ' $a$ '.

Fig. 9, shows the corresponding representation pattern of $\alpha \beta$ stator currents in the case of $25 \%$ of short circuited turns of phase ' $b$ ' and $5 \% \& 15 \%$ of short circuited turns of phase ' $a$ '. According to this figure the obtained pattern is an ellipse centered at $O_{\mathrm{f}}(10,9.5)$ and $O_{\mathrm{f}}(11,10)$ respectively, whose major axis orientation is associated to the faulty phase ' $b$ '.

Table 1 shows the fault severity index for both healthy and several faulty conditions. From this Table it is possible to verify that the fault severity index evolves from 0.2174 to 0.6604 in the case of a stator winding fault of $5 \%$ turns of phase ' $a$ ' and $7 \%, 10 \%, 25 \%$ turns of phase ' $b$ ' respectively, as long as the fault becomes more severe and the correspondent SFI becomes higher. In the case of a
Table 1. Fault severity index

\begin{tabular}{c|c|c|c|c}
\hline Test & Type & $R_{\mathrm{h}}$ & $R_{\mathrm{f}}$ & FSI \\
\hline 1 & Health & 3.6 & $/$ & 0 \\
\hline 2 & $\left(\mathrm{x}_{1}-\mathrm{x}_{4}\right)$ Fault & 3.6 & 4.6 & 0.2174 \\
\hline 3 & $\left(\mathrm{x}_{1} \cdot \mathrm{x}_{5}\right)$ Fault & 3.6 & 5.2 & 0.3077 \\
\hline 4 & $\left(\mathrm{x}_{1}-\mathrm{x}_{6}\right)$ Fault & 3.6 & 10.6 & 0.6604 \\
\hline 5 & $\left(\mathrm{x}_{2}-\mathrm{x}_{4}\right)$ Fault & 3.6 & 6.4 & 0.4375 \\
\hline 6 & $\left(\mathrm{x}_{2}-\mathrm{x}_{5}\right)$ Fault & 3.6 & 6.6 & 0.4545 \\
\hline 7 & $\left(\mathrm{x}_{2}-\mathrm{x}_{6}\right)$ Fault & 3.6 & 11.5 & 0.6870 \\
\hline
\end{tabular}

stator winding fault of $15 \%$ turns of phase ' $a$ ' and $7 \%, 10 \%$, $25 \%$ turns of phase ' $b$ ' respectively, the FSI becomes higher and the fault increases with the increase of short circuited turns.

\section{Conclusion}

In this paper a technique for detection and diagnosis of PMSM motor stator winding faults was presented. This method is based on the obtained stator currents and the correspondent Concordia transformation.

From the obtained current pattern it was used an image processing algorithm to identify if there is a motor fault. The measurements highlight that the locus of $\alpha \beta$ current characterises very well this kind of fault. Indeed, the obtained line varies from circular to elliptical shape when short-circuit occurs. The major axis of the measured ellipse magnitude and position traduce the fault severity in each of the two phases. According to this characteristic it was defined a fault severity factor (FSI) using the obtained radius data of the current patterns in healthy and faulty conditions. Experimental results demonstrated the ability of the proposed methodology to effectively be used to detect a stator winding fault. Its relatively simple implementation requirements and working in offline mode make the proposed approach an interesting alternative for condition monitoring.

\section{References}

[1] J. C. Urresty, J. R. Riba, L. Romeral, "A back-emf based method to detect magnet failures in PMSMs," IEEE Trans. On Magnetics, vol. 49, no. 1, pp. 591598, Jan., 2013.

[2] J. Arellano-Padilla, M. Sumner, and C. Gerada, "Winding condition monitoring scheme for a permanent magnet machine using high-frequency injection," IET Electric power applications, vol. 5, Iss. 1, pp. 8999, 2011.

[3] Y. Nyanteh, C. Edrington, S. Srivastava, and D. Cartes, "Application of artificial intelligence to realtime fault detection in permanent-magnet synchronous 
machines", IEEE Trans. On Industry Applications, vol. 49, no. 3, pp. 1205-1214, May/June, 2013.

[4] A. Sarikhani, and O. A. Mohamed, "Inter-turn fault detection in PM synchronous machines by physicsbased back electromotive force estimation," IEEE Trans. On Industrial Electronics, vol. 60, no. 8, pp. 3472-3484, Aug., 2013.

[5] J. A. Farooq, T. Rominosoa, A. Djerdir, and A. Miraoui, "Modelling and simulation of stator winding inter-turn faults in permanent magnet synchronous motors," Compel Journal, vol. 27, no. 4, pp.887-896, 2008.

[6] M. Hadef, M. R. Mekideche, and A. Djerdir, "Vector controlled permanent magnet synchronous motor (PMSM) drive with stator turn fault," Proceedings of XIX International Conference, ICEM, Rome, 6-8 Sep. 2010.

[7] T. Ishikawa, Y. Seki, and N. Kurita, “Analysis for fault detection of vector-controlled permanent magnet synchronous motor with magnet defect," IEEE Trans. On Magnetics, vol. 49, no. 5, pp. 2331-2334, May, 2013.

[8] Y. Da, X. Shi, and M. Krishnamurthy,“A new approach to fault diagnosis for permanent magnet synchronous machines using electromagnetic signature analysis, IEEE Trans. On Power Electronics, vol. 28, no. 8, pp. 4104-4112, Aug., 2013.

[9] B. L. R. Samaga, K. P. Vittal, "Comprehensive study of mixed eccentricity fault diagnosis in induction motors using signature analysis," Electrical power and energy systems, 35(2012), 180-185.

[10] B.M. Ebrahimi, J. Faiz, S. Lotfi-Fard, P. Pillay, "Novel indices for broken rotor bars fault diagnosis in induction motors using wavelet transform," Mechanical systems and signal processing 30(2012), 131-145.

[11] J. Faiz, M. Ojaghi, "Different indexes for eccentricity faults diagnosis in three-phase squirrel-cage induction motors: A review," Mechatronics 19(2009), 2-13.

[12] A. Soualhi, G. Clerc, and H. Razik, "Detection and diagnosis of faults in induction motor using an improved artificial and clustering technique", IEEE Trans. On Industrial Electronics, vol. 60, no. 9, pp. 4053-4062, Sep., 2013.

[13] Y. Gritli, L. Zarri, C. Rossi, F. Filippetti, G.A. Capolino, and D. Casadei, "Advanced diagnosis of electrical faults in wound-rotor induction machines", IEEE Trans. On Industrial Electronics, vol. 60, no. 9, pp. 4012-4024, Sep., 2013.

[14] F. Zidani, D. Diallo, M. E. H. Benbouzid, \& R. NaitSaid, "A fuzzy-based approach for the diagnosis of fault modes in a voltage-fed PWM inverter induction motor drive,", IEEE Trans. On Industrial Electronics, vol. 55, no. 2, pp. 586-593, Feb., 2008.

[15] H. H. Lee, N. T. Nguyen, \& J. M. Kwon, "Bearing fault diagnosis using fuzzy inference optimized by neural network and genetic algorithm," Journal of electrical engineering \& technology, vol. 2, no. 3, pp. 353-357, 2007.

[16] V. N. Ghate, \& S. V. Dudul, "Induction machine fault detection using generalized feed forward neural network," Journal of electrical engineering \& technology, vol. 4, no. 3, pp. 389-395, 2009.

[17] A. Medoued, A. Lebaroud, A. Laifa, \& D. Sayad, "Classification of induction machine faults using time frequency representation and particle swarm optimization," Journal of electrical engineering \& technology, vol. 9, no. 1, pp. 170-177, 2014.

[18] G. Didier, E. Ternisien, O. Caspary, and H. Razik, "Fault detection of broken rotor bars in induction motor using a global fault index," IEEE Trans. On Industry Applications, vol.42, no.1, pp.79-88, January/ February, 2006.

[19] J. F. Martins, V. Fernao Pires, and A. J. Pires, "Unsupervised neural network-based algorithm for an on-line diagnosis of three-phase induction motor stator fault," IEEE Trans. On Industrial Electronics, vol. 54, no. 1, pp. 253-264, Feb., 2007.

[20] L. M. R. Olivier, A. J. M. Cardoso, “Extended Park’s vector approach-based differential protection of threephase power tarnsformers," IET Electr. Power Appl, vol. 6, Iss. 8, pp. 463-472, 2012.

[21] S.M.A. Cruz, and A.J.M. Cardoso, "Stator winding fault diagnosis in three-phase synchronous and asynchronous motors, by extended park's vector approach," IEEE Trans. On Industry Applications, vol. 37, no. 5, pp. 1227-1233, Sep/Oct., 2001.

[22] J. F. Martins, V. F. Piers, and T. Amaral, "Induction motor fault detection and diagnosis using a current state pattern recognition," Pattern Recognition Letters, vol. 32, pp. 321-328, 2011.

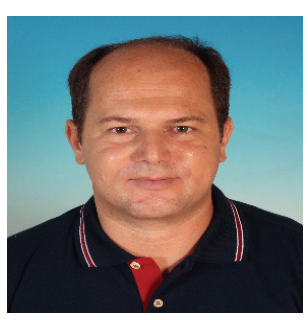

Mounir HADEF received the Engineer degree from the University of Jijel, Algeria, in 2000, and the Magister degree in Electrical Control from the University of Béjaia, Algeria, in 2002. He received his Ph.D. degree from the University of Jijel, Algeria, in 2012 From 2003 to 2007, he joined the department of Electrotechnics, University of Constantine, Algeria. He is currently an Assistant Professor at the University of Jijel. His research interest includes permanent magnets synchronous motors, induction motors, identification and optimization of electrical machines, inverse problem, computed-assisted analysis, modeling and control, fault tolerant control and fault diagnosis of electric machines. 


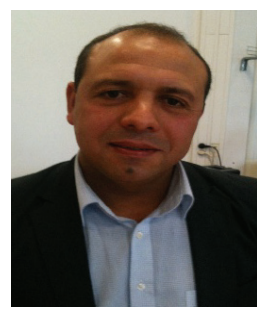

Abdesslem DJERDIR received the B.S. degree in electrical engineering from the National Institute of Electrical Engineering Bejaia, Algeria, in 1993 and the Ph.D. degree in electrical engineering from University of Franche Comté, Belfort, France, in 1999. Currently, he is an Associate Professor of electrical engineering in the Systems and Transport (SET) laboratory at University of Technology Belfort Montbéliard, France. He is also a member of the Fuel Cell Labratory (FC-LAB). He is habilitated to supervise scientific research since December 2007. His research interests include modeling and design of electric vehicle systems (electric machines, energy storage devices, and power converters). Since 2005 he developed his main researches on availability and high efficiency of electric drive trains in transport area by combining the experimental and theoretical approaches.

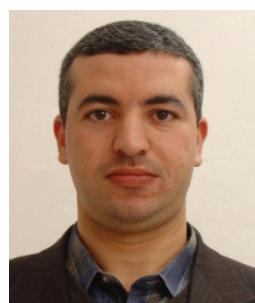

Nabil IKHLEF was born in Jijel, Algeria in 1975. After his first diploma as electrical engineer at the University of Jijel, he got the "assistant professor" degree, in 2003. He obtained his $\mathrm{PhD}$ Thesis in 2010 from the University of Batna (Algeria). He is now at the University of Jijel, as a teacher (Maitre de conferences A). Dr. Nabil Ikhlef is a member in the L2EI laboratory of the University of Jijel and is the author or co-author of about 50 works published or presented at international conferences. Now his axe of research is: the control, the modelling and simulation methods for equipment and process design.

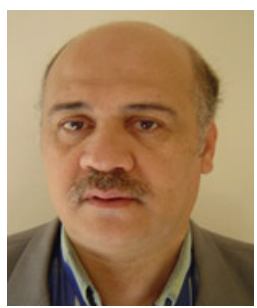

Mohamed Rachid MEKIDECHE was born in Jijel, Algeria in 1957. After his first diploma as electrical engineer at the USTO University at Oran, he joined, in 1981, the National Polytechnicas School at Algiers as an assistant and post-graduate student preparing a Magister. He got the "assistant professor" degree in 1986. After his $\mathrm{PhD}$ degree from the University of Nantes (France), he became "Maître de Conferences" and then Professor. He is now at the University of Jijel, as a teacher and Dean of the engineering faculty. Prof. Mohamed Rachid MEKIDECHE is now heading the L2EI laboratory of the University of Jijel and is the author or co-author of about 150 works published or presented at international conferences.

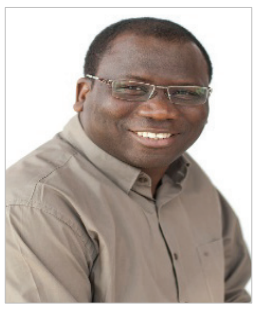

Abdoul N'DIAYE was born in 1968 in Mauritania where he carried out his primary and secondary school. In 1990, he passed his A-level and at the same time obtained a scholarship in Russia. After a training year at the Polytechnic institute university of St-Petersburg, he joined in September 1991 St-

Petersburg State University, in the power systems and automation department. In February 1997, he received his engineer degree in power systems from the same university. In October 1997, he started a postgraduate diploma (DEA) in France at Henry Poincaré Nancy I University and obtained his degree in March 1998. He continued his postgraduate studies preparing a thesis in electrical engineering called "Active compensation of torque ripples in permanent magnets synchronous motor" that he received in 2002. Since December 2005, he is a permanent member of the University of Technology of Belfort-Montbéliard. There, he is involved in research projects within the system and ground transportation laboratory (SeT). He is also taking part into teaching activities inside the Energy and Environment department. 